\title{
MULTISPECTRAL AND HYPERSPECTRAL SATELLITE DATA FOR ALTERATION MAPPING USING PARTIAL-SUBPIXEL ALGORITHM IN AN UNEXPLORED REGION
}

\author{
A. J. Abubakar ${ }^{1}$, M. Hashim ${ }^{2}$, A. B. Pour ${ }^{3}$, K. Shehu ${ }^{4}$ \\ ${ }^{1}$ Department of Geography, Faculty of Science, Kaduna State University P. M. B. 2339, Kaduna, Nigeria \\ - abusuhayl77@gmail.com \\ ${ }^{2}$ Geoscience and Digital Earth Centre (INSTeG), Research Institute for Sustainable Environment (RISE), \\ Universiti Teknologi Malaysia (UTM) - mazlanhashim@utm.my \\ ${ }^{3}$ Korea Polar Research Institute (KOPRI), Songdomirae-ro, Yeonsu-gu, Incheon 21990, Republic of Korea. \\ amin.beiranvand@kopri.re.kr \\ ${ }^{4}$ Department of Environmental Sciences, Faculty of science, Federal University Dutse, Jigawa State, Nigeria \\ kasaaga36.ks@gmail.com
}

KEY WORDS: ASTER, Hyperion, MTMF, Geothermal, Endmember spectra, Alteration zone,

\begin{abstract}
:
The focus of this paper is to comparatively evaluate the performance of ASTER and Hyperion data for target detection of hydrothermal alteration zones associated with geothermal (GT) springs in an unexplored savannah region. The study employed the partial subpixel unmixing Mixture Tuned Match Filtering algorithm for spectral information extraction using the multispectral and hyperspectral satellite data. In both cases, image endmember spectra specifically for kaolinite, alunite, and illite and calcite zones were selected and extracted by using the Analytical Imaging and Geophysics (AIG)-developed processing methods. The results show that the Hyperion, despite its distortions, can effectively discriminate associated alteration zones better than ASTER. Consequently, Hyperspectral data and analysis are thus recommended for use in similar unexplored regions for GT resource detection and monitoring.
\end{abstract}

\section{INTRODUCTION}

Mapping and identifying prospective geothermal (GT) resources can be challenging. This is especially the case in subtle systems not easily identifiable using conventional survey techniques. As observed from literature, different methods have been employed using remote sensing to identify GT targets, including; mapping thermal anomalies, minerals by proxy and structural faults (Abubakar et al., 2017). These studies are mostly in volcanic and tectonically active locations. It is however, not fully understood how these techniques could be implemented in aseismic environments with characteristically subtle GT features(Abubakar et al., 2017).

This study evaluated the applicability and performance of satellite multispectral and hyperspectral remote sensing data for mapping subtle GT systems using proxy mapping of associated alteration minerals in an uncharted tropical savanna region. Subtle GT systems are characterized by low temperature thermal springs, and sometimes may not necessarily have clear materialization of GT manifestations but however, indicate signs, imprints and relics of past GT activity such as hydrothermally altered rock deposits that can be used to identify and or infer on their characteristics. The Yankari Park (figure 1) is an area in northeastern Nigeria characterized by several hotsprings and consequently hydrothermally altered rocks (Abubakar et al., 2017). These provides a suitable test area for investigation of subtle GT features which are challenging to detect using conventional methods.
The objective of the present study is to test and compare the effectiveness of the ASTER and Hyperion visible near infrared and shortwave infrared (VNIR-SWIR) bands in identifying and discriminating associated altered zones, specifically the; argillic-phyllic and propylitic zones which manifest diagnostic spectral characteristics within the (VNIR-SWIR) portions of the electromagnetic spectrum (Kruse et al., 2003). The Mixture Tuned Match Filtering (MTMF) (Boardman and Kruse, 2011), which is a partial sub-pixel spectral mapping algorithm was used for spectral information extraction.

\section{STUDY AREA GEOLOGY}

The study area is Yankari Park, located within Latitude 9.75000N, and Longitude 10. 50000E in Bauchi State, northeastern Nigeria (Figure 1). It covers about 2,244 square kilometers (866 sq. mi). Thermal springs in the Park include; Dimmil, Gwana, Mawulgo and Wikki. Geologically, it is within the Kerri formation characterized by Neogene to Mesozoic older sedimentary rocks which is composed of sandstone, silt stones, kaolinites, grits and clays (Abubakar et al., 2017). The processes around the springs are influenced by the nature of fractured sediments and permeability within the quartzite caused by intergranular pore spaces together with the fracturing of the relatively competent quartzite (Osagie, 2008). Consequently, kaolinite, ironstones, carbonate, quartz and sulfates, which are the hydrothermal alteration minerals predominantly identified, are associated with surface manifestations of the hot springs in the study area (Ajakaiye $e t$ al., 1988)

\footnotetext{
* Corresponding author
} 


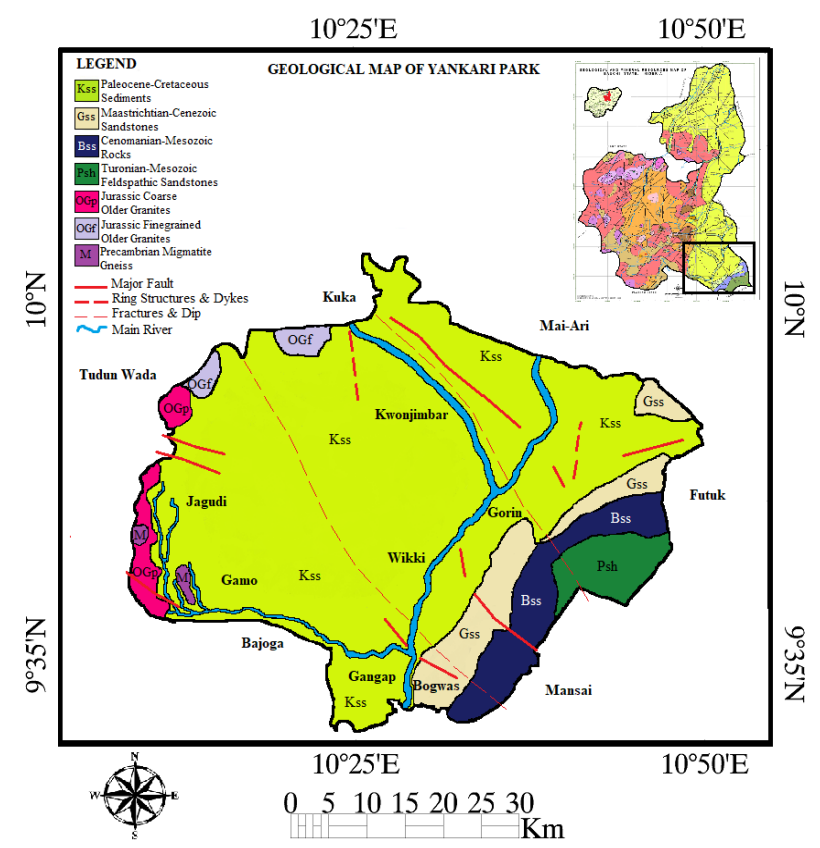

Figure 1. The study area geology map of Yankari Park showing region (A) location where analysis is conducted on ASTER and Hyperion datasets

\section{MATERIALS AND METHODS}

\subsection{Remote Sensing data}

ASTER level 1T (AST_L1T, path/raw, 187/53) data of 25th January 2006 acquisition date covering the Yankari Park were obtained from the LPDAAC data pool. The ASTER level 1T is a Precision Terrain Corrected Registered At-Sensor Radiance that has been geometrically rectified, and turned to a north-up Universal Transverse Mercator (UTM) $32 \mathrm{~N}$ projection with WGS 84 Datum.

ASTER is characterized by 14 spectral bands with a spatial resolution of $15 \mathrm{~m}$ to $90 \mathrm{~m}$ depending on the bands. The VNIR subsystem of ASTER has three recording channels between 0.52 and $0.86 \mu \mathrm{m}$ with a spatial resolution of up to $15 \mathrm{~m}$. The SWIR subsystem of ASTER has six recording channels from 1.6 to $2.43 \mu \mathrm{m}$, at a spatial resolution of $30 \mathrm{~m}$ and the TIR has five recording channels, covering the 8.125 to $11.65 \mu \mathrm{m}$ wavelength region with spatial resolution of $90 \mathrm{~m}$

A cloud-free level 1T Hyperion image (scene ID: EO1H1870532002318110PY_1T) covering the southwestern area of the Yankari Park was also obtained through the U.S. Geological Survey Earth Resources Observation and Science Center (EROS) (http://earthexplorer.usgs.gov). It was acquired on March 22, 2003. The Hyperion image was also pregeoreferenced to the UTM zone 32 North projection using the WGS-84 datum.

The image used in this study is a GeoTIFF Product, which is radiometrically and systematic geometrically corrected with ground control points (Dwyer, 2006). The Hyperion sensor is characterized by a high resolution data capable of resolving 220 spectral bands by two spectrometers one in the VNIR (approximately $0.4-1.0 \mu \mathrm{m}$ ) and another SWIR spectrometer (approximately $0.9-2.5 \mu \mathrm{m}$ ) with a $10 \mathrm{~nm}$ spectral resolution and a 30-meter spatial resolution from an orbit of 705-km (Dwyer, 2006).

\subsection{Atmospheric Correction}

Both ASTER and Hyperion data were atmospherically corrected using The Fast Line-of-site Atmospheric Analysis of Spectral Hypercubes (FLAASH) algorithm. The FLAASH atmospheric correction algorithm is developed by the Air force Research Laboratory, Space Vehicles Directorate (AFRL/VS) and Spectral Sciences, Inc. (SSI) (Felde et al., 2003) to aid the analysis of VNIR-SWIR Multispectral and Hyperspectral imaging sensors.

The algorithm derives its first-principles physics-based calculations from the MODTRAN4 radiative transfer code (Anderson et al., 2002). To perform the FLAASH absolute correction, the ENVI classic software calibration utilities was used. The images are thus converted from radiance to reflectance to facilitate subsequent spectral analysis.

\subsection{Data Processing}

A spatial subset of both ASTER (500 x 700 pixels) and Hyperion $(400 \times 600$ pixels $)$ were made covering the focused area designated (A). The Hyperion data was initially subjected to preprocessing steps including; removal of bad bands, destriping of vertical stripes and Smile effect correction to rectify some of its distortions and improve spectral signature extraction (Goodenough et al., 2003).

Subsequently, the AIG developed processing routine (Kruse et al., 2003) was followed by using the ENVI 5.1 spectral hourglass procedure which sequentially include; minimum noise fraction (MNF) transform, pixel purity index (PPI), nDimensional visualization and selection of spectral endmembers (EM). Identified EM were verified using the ASTER spectral library for reference by considering the diagnostic shape and position of absorption feature, the minerals are characterized as kaolinite, illite, alunite, and calcite (see figure 2).

Likewise for the ASTER data, similar image spectral EM are extracted in the designated areas as identified in the Hyperion in order to facilitate comparison. Consequently, kaolinite (red), alunite (green) represent argillic alteration mineral indicators, illite (blue) represents phyllic alteration and calcite (yellow) represents propylitic alteration zones respectively (Figure 2). These were employed as spectral EM for the MTMF analysis (Boardman and Kruse, 2011).

(a)

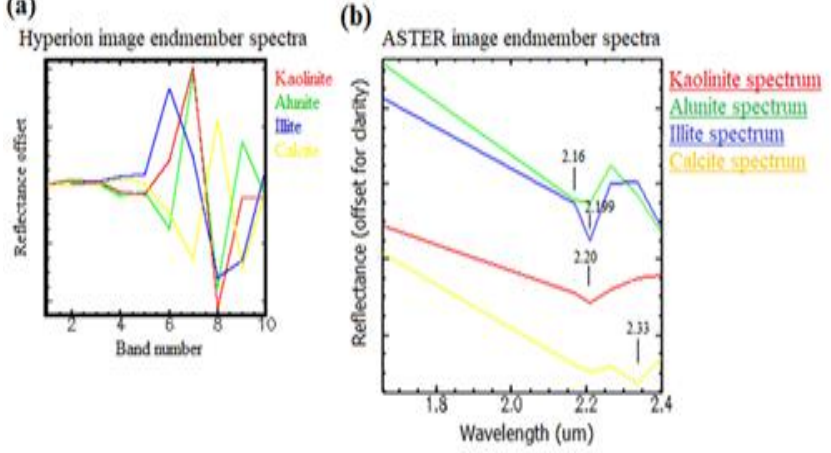




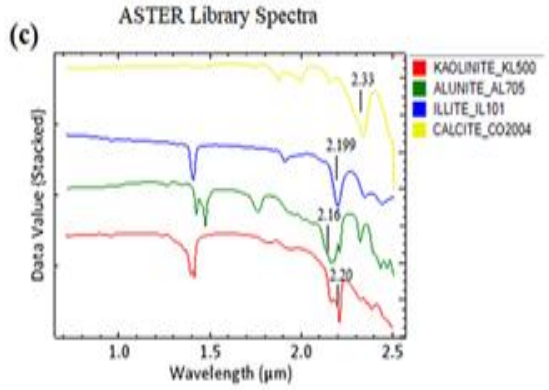

Figure 2: Endmember spectra selected from ASTER and Hyperion images compared to ASTER spectral library and used for spectral analysis

\section{RESULTS AND DISCUSSIONS}

\subsection{Result of MTMF at region of interest (A) using ASTER}

The result of the MTMF analysis for the 4 EM are first loaded as RGB in figure 3(a) using the MF score image for kaolinitealunite-illite-calcite which shows all pixels classified including false positives and errors. The mixture tuning was then employed and scatter plots of MF score against infeasibility (figure 4) are plotted and examined, in which pixels having the lowest infeasibility and higher MF score of about 0.6-1 where an MF score of 1 denotes a perfect match (Boardman and Kruse, 2011), were approximately selected and used to produce the subpixel abundance map in figure $3(\mathrm{~b})$.

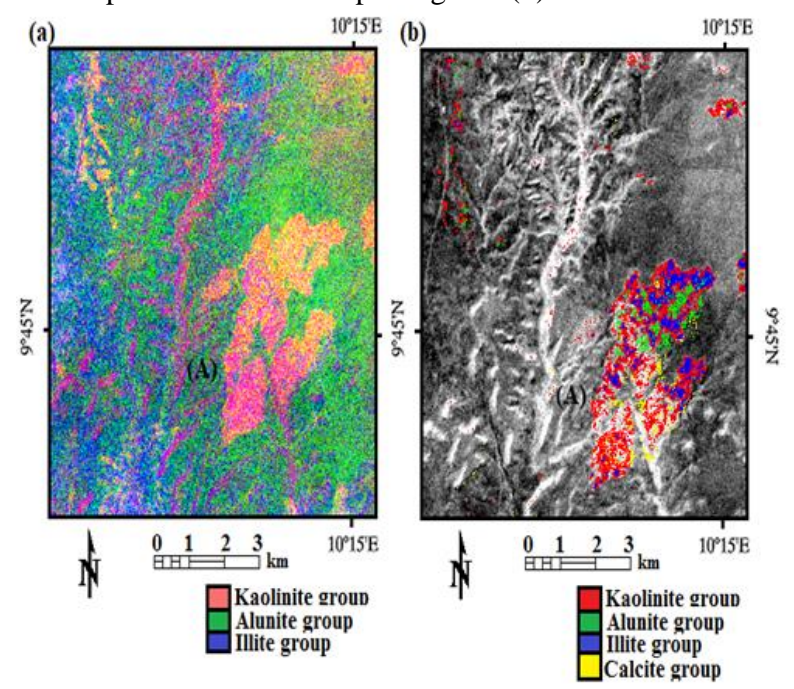

Figure 3: (a) MF score RGB for selected endmembers (ASTER) showing incoherent image with errors. (b) MTMF subpixel abundance image produced using mixture tuning from figure 4

The result show pixels predominantly discriminated as kaolinite-red (argillic alteration), encircling alunite (argillic) and illite (phyllic) subpixel abundances especially around (A). Few pixels are classified as calcite-yellow (propylitic alteration), by selecting pixels with $0.6-1$ (equivalent to 60$100 \%$ subpixel abundances).

\subsection{Result of MTMF at region of interest (A) using Hyperion}

The MTMF was similarly applied to the Hyperion SWIR using the $4 \mathrm{EM}$ as alteration indicators. The result of MF score image and MTMF subpixel abundances is shown in figure 5(a) and (b). Figure 5(b) is also produced using mixture tuning as indicated in figure 6 , which shows pixels with low infeasibility selected within the range of high MF scores of $70-100 \%, 80-$ $100 \%, 75-100 \%$ and $80-100 \%$ for kaolinite, alunite, illite and calcite respectively.
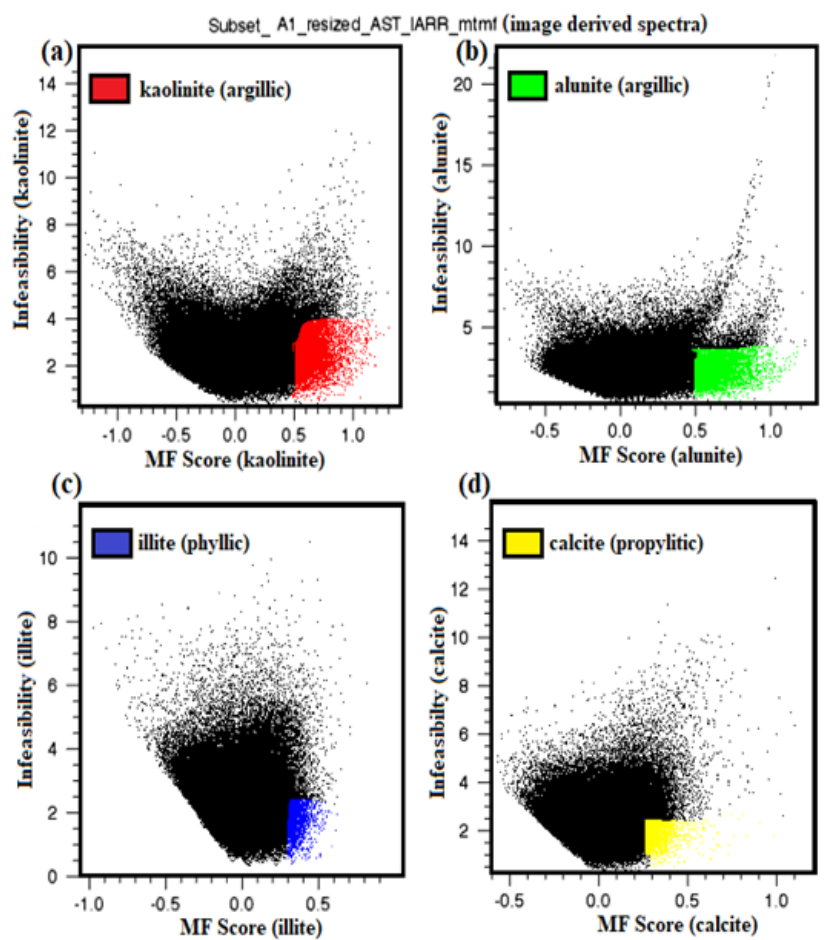

Figure 4: 2-Dimensional scatter plots used to map valid alteration detections (A) for 4 endmembers (ASTER endmember spectra) as reference

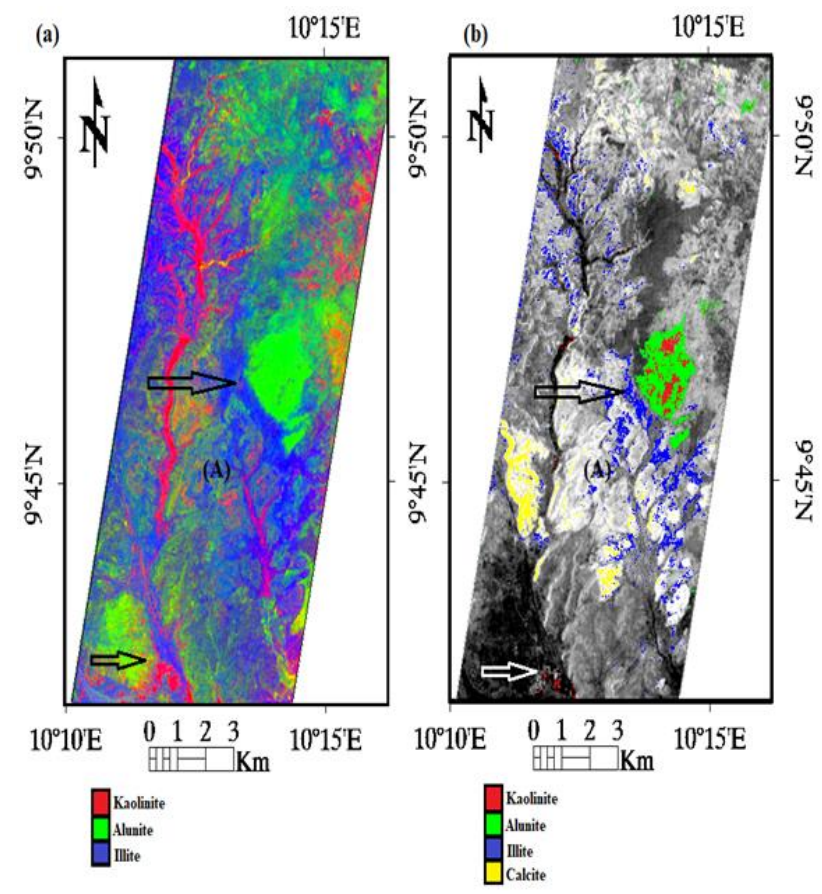

Figure 5: (a) MF score RGB for selected endmembers (Hyperion) showing incoherent image with errors. (b) MTMF subpixel abundance image produced using mixture tuning in figure 6 

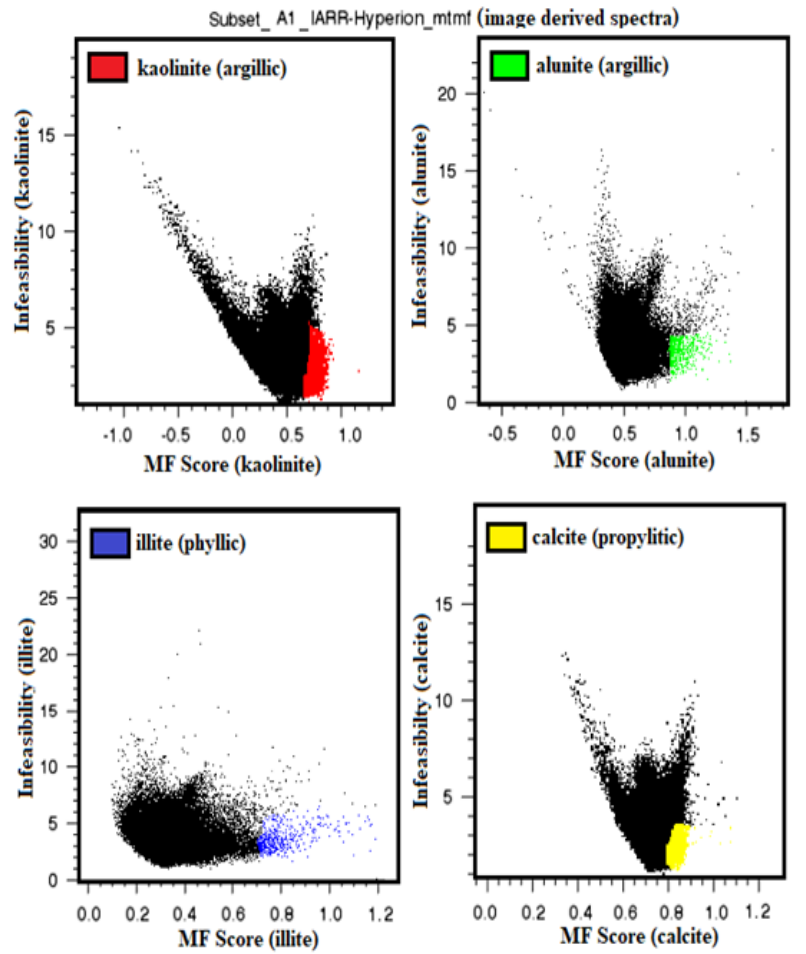

Figure 6: 2-Dimensional scatter plot used to map valid alteration detections at (A) for 4 endmembers in figure 5(b)

It is observed from the result that the MF score RGB image in figure 5(a) is moderately well-defined due to the spectral fidelity of the Hyperion which clearly indicates alteration zones e.g. the alunite-kaolinite zones are well mapped around (A) but the image still contains errors as all pixels including vegetation and background data are discriminated. The mixture tuning was used to select valid detections having higher MF score of the range of close to 1 or $100 \%$ for all the $4 \mathrm{EM}$ (see figure 6), signifying that using the Hyperion gave higher accuracy of valid detections ranging from (0.7-1) equivalent to $70-100 \%$ (e.g. an MF score of 0.9 means that the pixel contains $90 \%$ of the target/end member of interest (Boardman and Kruse, 2011), thus narrowing targets better than when compared to using the ASTER data in which case, pixels of averagely 50-100\% were selected to create coherent subpixel abundance maps. The Hyperion MTMF result in figure 5(b) also shows a clear discrimination of illite (blue) and calcite (yellow) for phyllic and propylitic alteration zones respectively. However, the argillic (kaolinite-alunite) abundance in (figure 5(b) were observed to both occur concentrically at region of interest (A), further corroborating (A) as predominantly argillic.

\subsection{Validation of Results}

The results of this investigation were further validated using comprehensive GPS field sampling of altered rocks from sampled areas. Laboratory verification using ASD and X-Ray diffraction analysis of altered rock samples indicates presence of Kaolinite, Hematite and Quartz

\section{CONCLUSION}

In conclusion, the results of this investigation demonstrated that alteration mapping using the Hyperion data was found to provide more accurate results than ASTER data. For instance, the results of MTMF using Hyperion produced a coherent image by selecting pixels with subpixel abundance within the range of 0.8, 0.9-1.0 of match filtering (MF) score and low infeasibility (equivalent to $80,90-100 \%$ ) as compared to ASTER data having an average of 0.5, 0.6-1.0 of MF score (equivalent to 50,60-100\%) of subpixel abundance of valid detections for alteration mineral indicators of GT importance. This can be attributable to Hyperion's better spectral fidelity as compared to ASTER's moderate spectral resolution.. Results of this study signifies the need for integrative use of both sensors for hydrothermal alteration mapping and narrowing targets in the prefeasibility stage mapping of subtle GT systems.

\section{ACKNOWLEDGEMENTS}

The authors also wish to acknowledge the Kaduna State University, Nigeria, Universiti Teknologi Malaysia and Korea Polar Research Institute for providing the facilities for this investigation.

\section{REFERENCES}

Abubakar, A. J., Hashim, M. and Pour, A. B. (2017). Identification of Hydrothermal Alteration Minerals Associated with Geothermal System Using Aster and Hyperion Satellite Data: A Case Study from Yankari Park, Ne Nigeria. Geocarto International, 1-57

Ajakaiye, D., Olatinwo, M. and Scheidegger, A. (1988). Another Possible Earthquake near Gombe in Nigeria on the 1819 June 1985. Bulletin of the Seismological Society of America, 78(2), 1006-1010.

Anderson, G. P., Felde, G. W., Hoke, M. L., Ratkowski, A. J., Cooley, T. W., Chetwynd Jr, J. H., Gardner, J., Adler-Golden, S. M., Matthew, M. W. and Berk, A. (Year) Published. Modtran4Based Atmospheric Correction Algorithm: FLAASH (Fast Lineof-Sight Atmospheric Analysis of Spectral Hypercubes). Aero Sense 2002, 2002. International Society for Optics and Photonics, 65-71.

Boardman, J. W. and Kruse, F. A. (2011). Analysis of Imaging Spectrometer Data Using N-Dimensional Geometry and a Mixture-Tuned Matched Filtering Approach. IEEE Transactions on Geoscience and Remote Sensing, 49(11), 4138-4152.

Dwyer, M. J. L. (2006). Remotely Sensed Data Available from the Us Geological Survey Eros Data Center. Earth Science Satellite Remote Sensing. (pp. 18-51). Springer.

Goodenough, D. G., Dyk, A., Niemann, K. O., Pearlman, J. S., Chen, H., Han, T., Murdoch, M. and West, C. (2003). Processing Hyperion and Ali for Forest Classification. IEEE transactions on geoscience and remote sensing, 41(6), 13211331.

Kruse, F. A., Boardman, J. W. and Huntington, J. F. (2003). Comparison of Airborne Hyperspectral Data and Eo-1 Hyperion for Mineral Mapping. IEEE Transactions on Geoscience and Remote Sensing, 41(6), 1388-1400.

Osagie, E. O. (2008). Seismic Activity in Nigeria. The Pac Jour Sci and Tech, 9(2), 1-6.

Revised August 2019 